\title{
Implementation and evaluation of the International Electrotechnical Commission specification for tidal stream energy resource assessment: A case study
}

\author{
V. Ramos*, John V. Ringwood \\ Centre for Ocean Energy Research (COER), Maynooth University, Co. Kildare, Ireland
}

\section{A R T I C L E I N F O}

\section{Article history:}

Received 6 June 2016

Received in revised form 27 July 2016

Accepted 25 August 2016

\section{Keywords:}

Tidal stream energy

IEC-62600-201

Orkney Region

TAEP

Delft3D-Flow

\begin{abstract}
A B S T R A C T
Over the next decades, tidal stream energy aims to become a fully commercially viable energy source. For this purpose, complete knowledge regarding tidal stream resource assessment is essential. In this context, the International Electrotechnical Commission has developed a technical standard for the assessment of the tidal stream resource, "IEC 62600-201 TS: Marine energy - Wave, tidal and other water current converters - Part 201: Tidal energy resource assessment and characterisation", offering a vast set of recommendations in the fields of data collection, numerical modelling, data analysis and reporting of the results with the purpose of standardising tidal stream resource characterisation. The standard divides resource assessments into two different classes: feasibility and layout design. The model setup procedure (mesh resolution, boundary conditions) and the computational effort required vary significantly from one class to another. For these reasons, the objective of the present work is to explore the proposed standard using the Orkney Region (N Scotland) as a case study. Overall, it was found that the standard works well, offering a detailed characterisation of the tidal resource; however, in order to improve its manageability, some aspects related to the grid resolution requirements and the approach to model a tidal energy converter could be revisited for future editions.
\end{abstract}

(c) 2016 Published by Elsevier Ltd.

\section{Introduction}

Over the last two decades, different policies have been developed with the purpose of increasing the contribution of renewable energy sources to the energy mix [1]. In this context, marine energy has attracted a great deal of attention due to its large energy potential [2]. Among the different marine energy modalities, tidal stream energy stands out [3]. Tidal stream power taps the kinetic energy of the currents caused by the tidal height variations [4]. When compared with other sources of renewable energy, tidal stream power presents significant advantages: (i) the resource can be predicted in advance due to the astronomical nature of the driving force; (ii) the load factor is comparatively high due to the properties of the fluid; and (iii) land occupation is minimal [5].

On the other hand, tidal stream power is not without some downsides: (i) the Tidal Energy Converter (TEC) technology is still in its infancy (though it is making good progress) [5]; (ii) a limited number of locations are available for tidal current exploitation due

\footnotetext{
* Corresponding author.

E-mail address: josevictor.ramoscastro@nuim.ie (V. Ramos).
}

to water depth limitations [6]; and (iii) potential impacts may result from TEC operation on the marine environment. On these grounds, [7] shows the potential impacts on different coastal processes. In addition, [8] investigates the alterations on the sediment dynamic patterns. Finally, [9] proves that tidal stream energy can modify the estuarine circulation patterns in tidally driven estuaries.

Despite all these limitations, tidal stream energy has still attracted a great deal of attention both within the academic and industrial communities, which has translated into a large number of tidal resource assessments all over the world [10]. These resource assessments have been mainly carried out by means of hydrodynamic numerical models validated against field measurements [11]. However, the approaches used vary significantly for different parameters, such as the time scale of the assessments, the effects derived from the wave-current interaction, the inclusion of the TEC operation in the modelling strategy for a correct estimation of the tidal resource and performance of different TEC technologies and some aspects related to the economic point of view. In this context, [12] highlights the importance of the wavecurrent interaction for an appropriate estimation the tidal resource. Furthermore, [13] deals with the potential variations in 
the magnitude of the tidal resource due to the presence and operation of a tidal farm. Finally, [14] adds some aspects related to the economic point of view to assess potential sites for tidal energy exploitation.

As a result, the International Electrotechnical Comission (IEC) has recently put forward a set of recommendations to develop a uniform methodology with the aim of ensuring consistency and accuracy in tidal resource assessment: "IEC 62600-201 TS: Marine energy - Wave, tidal and other water current converters - Part 201: Tidal energy resource assessment and characterisation" (from now on referred as IEC-62600-201) [15]. IEC-62600-201 classifies the tidal resource assessments into two different categories, feasibility and layout design, denoted as Stage 1 and 2, respectively. Stage 1 assessments are intended to obtain a first approximation of the tidal stream energy resource over a relative large area (i.e. estuary or channel) with a medium level of uncertainty. Stage 2 assessments are used to obtain a detailed characterisation in a specific area to determine the TEC Annual Energy Production (TAEP) with a low degree of uncertainty. In addition, IEC-62600-201 also offers a detailed series of recommendations regarding the procedure to follow in the fields of data collection, numerical modelling, data analysis and reporting of the results. Furthermore, the numerical setup varies considerably from Stage 1 to Stage 2 in terms of boundary conditions, spatial resolution and physical processes to be considered, which presents a significant impact on the level of effort required in the modelling process.

Consequently, this work aims to focus on: (i) The evaluation of the two different stages of resource assessment proposed by IEC62600-201 in terms of uncertainty of the estimated TAEP and the effort required in the model setup and application with special emphasis on the computational demands and (ii) the provision of feedback into the IEC-62600-201 standard with the aim of offering practical recommendations to the users and future edits to be considered during the maintenance of the IEC-62600-201.

For this purpose, the Orkney Region (N Scotland) was used as a case study, which is one of the world's most promising locations to harvest the tidal stream resource [16]. Due to its large energetic potential [17], the European Marine Energy Centre (EMEC) has set up several test sites, providing the opportunity to test fullscale grid-connected prototype devices for both wave and tidal conditions [18]. Regarding tidal stream energy, two test sites are available: (i) the Fall of Warness (Fig. 1) a grid-connected facility, which offers five test berths at depths ranging from $25 \mathrm{~m}$ to 50 $m$ in an area of approximately $8 \mathrm{~km}^{2}$ and (ii) the scale tidal test site at Shapinsay Sound (Fig. 1), a non-grid connected tests site, which provides TEC developers with the opportunity to test their prototypes in real sea conditions. Although detailed studies assessing the tidal stream resource have been conducted in the region [17], none of them has been carried out following the IEC-62600-201 methodology. For all the above mentioned reasons, this region appears as an excellent location to evaluate the main aspects related to the numerical modelling of IEC-62600-201.

\section{Materials and methods}

This section presents the materials and methods used in the present paper, dealing with the most important aspects of IEC62600-201 (Section 2.1) and the different modelling approaches implemented in this investigation (Sections 2.2-2.4).

\subsection{IEC 62600-201 TS}

The main goal of the IEC-62600-201 standard is to provide a uniform methodology in order to ensure consistency and accuracy in the modelling, measurement, characterisation and analysis of the tidal stream resource with the aim of accurately estimating the TEC Annual Energy Production (TAEP) at locations suitable for the installation of a tidal farm. In this section, only the main characteristics of the modelling aspects of IEC-62600-201 will be presented. For further details in other fields, such as data measurement and data analysis, the readers are referred to the IEC-62600201 document [15].

As mentioned in Section 1, the technical specification classifies tidal resource assessment into two different classes: feasibility and layout design, which are dentoted as Stages 1 and 2, respectively. The main characteristics of each class are summarised in Table 1.

As can be observed in Table 1, Stage 1 studies are focused on investigating the tidal resource over a particular area of study, such as an estuary or a channel, with the aim of assessing the viability of the installation of a tidal farm. On the other hand, Stage 2 studies are focused on generating detailed and accurate information on the energy resource to determine the most ideal locations and typology of TEC deployments, as well as their power production. The decrease in the level of uncertainty from Stage 1 to Stage 2 results from different refinement of procedures such as: (i) measurements
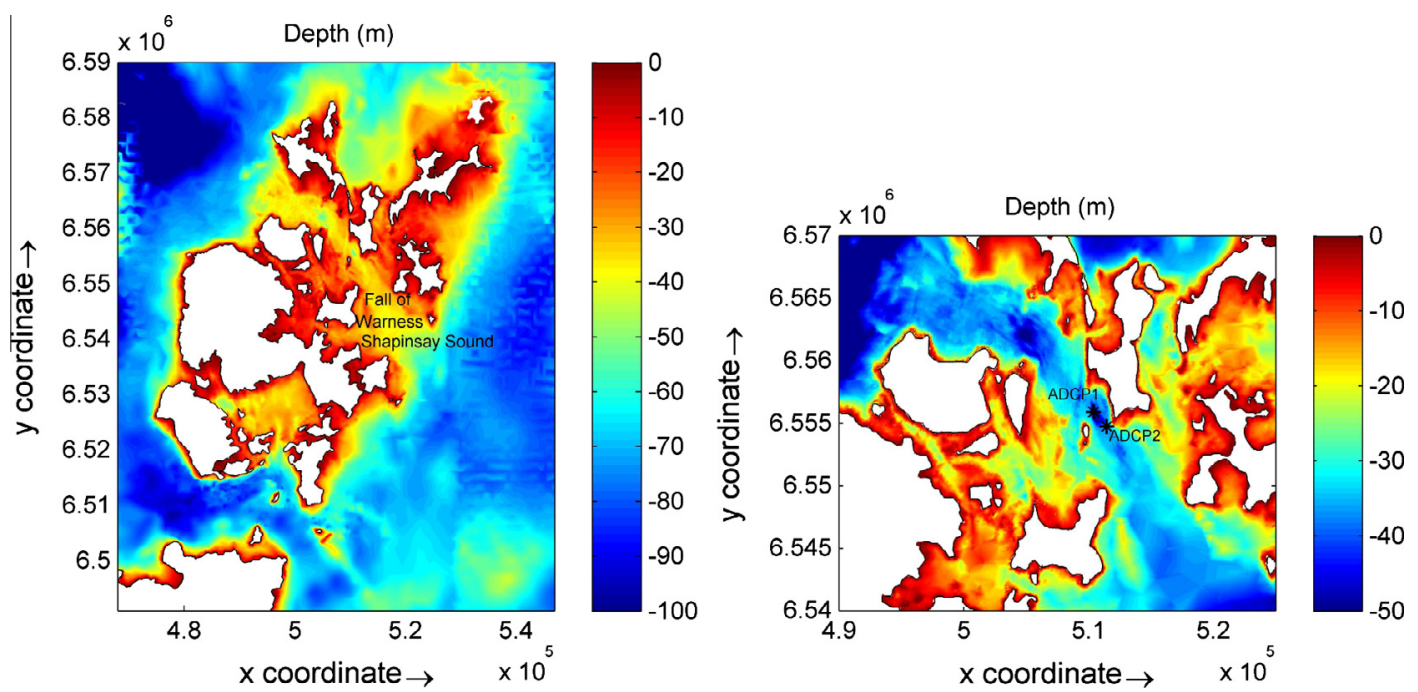

Fig. 1. Orkney Region (left) and Fall of Warness test site (right). 
Table 1

Resource assessment stages IEC-62600-201.

\begin{tabular}{cccc}
\hline Stage & Aim & Area & Level of uncertainty \\
\hline Stage 1 & Feasibility & Estuary/channel & Medium \\
Stage 2 & Layout design & Development site & Low
\end{tabular}

and/or modelling over longer periods; (ii) availability of additional, and/or higher quality measurements; (iii) finer discretisation in space and time; (iv) use of improved boundary conditions and (v) improvements in modelling techniques during the evolution of the project.

The model setup requirements may vary considerably from one class to another in terms of (i) physical processes to be considered (wave-current interaction, baroclinic flows, etc.); (ii) boundary conditions (i.e. min. number of harmonic constituents required); (iii) spatial resolutions (vertical resolution 2D vs 3D, min. horizontal grid resolution) and (iv) temporal resolution [19]. All these requirements are summarised in Table 2.

Regardless of the class considered, the main objective is to determine the TAEP, which can be computed according to the following expression:

$T A E P=N_{h} \cdot A \cdot \sum_{i=1}^{N_{B}} P_{i}\left(U_{i}\right) \cdot f_{i}\left(U_{i}\right)$,

where $N_{h}$ is the number of hours in the simulated year, $A$ is the expected TEC availability, $N_{B}$ represents the total number of velocity bins in the TEC power curve, $P_{i}\left(U_{i}\right)$ describes the power output generated by the $i$ th velocity bin of the TEC power curve, $U_{i}$ stands for the mean current velocity of the $i$ th bin of the TEC power curve, and $f_{i}\left(U_{i}\right)$ describes the proportion of time for which the mean current velocity falls within the $i$ th velocity bin of the TEC power curve.

Depending on the nature of the tidal project, the requirements for the hydrodynamic models to calculate the TAEP may differ significantly. For instance, in projects in which the total power output is expected to be less than $10 \mathrm{MW}$ and/or $2 \%$ of the theoretical energy resource, the TAEP may be computed directly from the time series of velocities obtained from a hydrodynamic model validated against field measurements. In addition, for these projects the TAEP may also be calculated from direct field measurements at the locations of interest. Conversely, for larger projects (i.e. more than $10 \mathrm{MW}$ and/or $2 \%$ of the theoretical energy resource) IEC62600-201 does require the representation of the TEC operation in the hydrodynamic model to account for the potential effects on the magnitude of tidal flow velocities and, therefore, to represent them on the velocity probability distribution. For the purpose of modelling the TEC operation within a hydrodynamic model, IEC62600-201 proposes methodologies widely used in the literature such as the momentum sink approach [13], which consists of

Table 2

IEC-62600-201 model setup recommendations.

\begin{tabular}{ccc}
\hline Component & Stage 1 & Stage 2 \\
\hline Modelling & & \\
Num. of harmonic constituents & $4-8$ & $8-12$ \\
Vertical discretisation & $2 \mathrm{D}$ & $3 \mathrm{D}$ \\
Min. grid resolution & $<500 \mathrm{~m}$ & $<50 \mathrm{~m}$ \\
$\quad$ Period of run & $>35$ days & $>35$ days \\
Energy extraction impacts & $\circ$ & $*$ \\
Physical data requirement & & $*$ \\
Wave characteristics & $*$ & $*$ \\
Meteorological data & $*$ & $*$ \\
Flow structure/eddies/turbulence & $*$ & $*$ \\
Stratification, Seawater density and sediment & $*$ & \\
measurement & & \\
\hline
\end{tabular}

- Mandatory; * Recommended; 。 No mandatory. including an additional retarding force in the momentum equations of the model that represents the operation of TECs [20].

According to IEC-62600-201, the models must be validated for each class of resource assessment. IEC-62600-201 also establishes that the model validation should be achieved by comparing the TAEP results obtained from the field measurements and computed time-series of velocity at a specific location, by using a TEC technology as a reference. In the absence of a TEC as reference, the validation parameter would be the velocity probability distribution, $f_{i}\left(U_{i}\right)$. For Stage 2 assessments, the comparison should be carried out at different critical depths alongside the water column. For Stage 1 studies, in which a 2D modelling approach is used, tidal velocities at specific water depths should be estimated by means of an appropriate vertical velocity profile. In any case, IEC-62600201 does not set either a minimum number of validation points or a statistical criteria to consider the model successfully validated.

Finally, IEC-62600-201 has proposed a simplified methodology to estimate the TAEP using harmonic analysis. This methodology consists of determining the amplitude and phase of the main harmonic components from short time-series of velocity (35-50 days), which can be obtained from field measurements or modelled data, and then, to use these constituent data to extrapolate the annual time-series of velocity. As a result, a remarkable reduction in the computational effort may be achieved, especially in comparison to a hydrodynamic model; however, it may not be appropriate for regions in which non-tidal and highly seasonal factors such as wind or river discharges play an important role in the hydrodynamic behaviour of the region.

\subsection{Delft3D-Flow numerical model}

With the aim of determining the tidal stream energy resource in the area of study, the open source hydrodynamic model Delft3DFlow was used [21]. Delft3D-Flow is a finite difference code, which solves the unsteady shallow water equations in two (depthaveraged) or three dimensions. The system of equations consists of the horizontal and vertical equations of motion, the continuity equation, and the transport equations for conservative constituents. The flow is forced by the tide at the open boundaries, wind stress at the free surface and pressure gradients due to free surface gradients (barotropic) or density gradients (baroclinic). Source and sink terms are included in the equations to model the discharge and withdrawal of water. Thus, the main equations solved by the model are:

(i) The continuity equation:

$$
\frac{\partial u}{\partial x}+\frac{\partial v}{\partial y}+\frac{\partial w}{\partial z}=Q
$$

where $x, y$ and $z$ represent the east, north and vertical axes, respectively; $u, v$ and $w$ are the velocity components in the $x, y$ and $z$ directions, respectively; and $Q$ represents the intensity of mass sources per unit area.

(ii) The momentum equations in the horizontal direction:

$$
\begin{aligned}
\frac{D u}{D t}= & f v-g \frac{\partial \zeta}{\partial x}-\frac{g}{\rho_{0}} \int_{z^{\prime}=z}^{z^{\prime}=\zeta} \frac{\partial \rho}{\partial x} \mathrm{~d} z^{\prime}+v_{h}\left(\frac{\partial^{2} u}{\partial x^{2}}+\frac{\partial^{2} u}{\partial y^{2}}\right) \\
& +v_{v}\left(\frac{\partial^{2} u}{\partial z^{2}}\right), \\
\frac{D v}{D t}= & -f u-g \frac{\partial \zeta}{\partial y}-\frac{g}{\rho_{0}} \int_{z^{\prime}=z}^{z^{\prime}=\zeta} \frac{\partial \rho}{\partial y} \mathrm{~d} z^{\prime}+v_{h}\left(\frac{\partial^{2} v}{\partial x^{2}}+\frac{\partial^{2} v}{\partial y^{2}}\right) \\
& +v_{v}\left(\frac{\partial^{2} v}{\partial z^{2}}\right),
\end{aligned}
$$


where $\zeta$ stands for the free surface elevation relative to a reference plane $(z=0), g$ is the gravitational acceleration, $\rho$ and $\rho_{o}$ are the density and reference density of sea water, respectively; $f$ is the Coriolis parameter and $v_{h}$ and $v_{v}$ are the horizontal and vertical eddy viscosity coefficients, respectively.

(iii) The momentum equation in the vertical direction:

Under the shallow-water assumption, the conservation of momentum in the vertical direction is simplified to the hydrostatic pressure, $p$, distribution:

$\frac{\partial p}{\partial z}=-\rho g$

(iv) The transport equation:

$\frac{D c}{D t}=D_{h}\left(\frac{\partial^{2} c}{\partial x^{2}}+\frac{\partial^{2} c}{\partial y^{2}}\right)+D_{v} \frac{\partial^{2} c}{\partial z^{2}}-\lambda_{d} C+R_{s}$,

where $c$ represents either salinity or temperature, $\lambda_{d}$ represents a first order decay process, $D_{h}$ and $D_{v}$ are the horizontal and vertical eddy diffusivity coefficients, respectively and, finally, $R_{S}$ is the source term per unit area.

\subsection{TEC modelling in Delft3D-Flow}

In order to take into account the potential impacts on the total energy production of a tidal array due to the local alterations on the hydrodynamics [22], the effects related to the operation of the TECs must be simulated. Despite a large number of methods having been used to model the operation of a TEC within largescale hydrodynamic codes like Delft3D-Flow, the momentum sink approach is one of the most widely used [23]. Specifically, Delft3DFlow offers the so-called "Porous Plate" tool [21], which can be used to simulate the operation of a TEC [20] by adding two momentum sink terms $\left(M_{x}, M_{y}\right)$ to the right-hand side of the momentum equations (Eqs. (3) and (4)), which account for the loss of momentum of the flow, due to the presence of the TECs.

$\frac{D u}{D t}=f v-g \frac{\partial \zeta}{\partial x}-\frac{g}{\rho_{0}} \int_{z^{\prime}=z}^{z^{\prime}=\zeta} \frac{\partial \rho}{\partial x} \mathrm{~d} z^{\prime}+v_{h}\left(\frac{\partial^{2} u}{\partial x^{2}}+\frac{\partial^{2} u}{\partial y^{2}}\right)+v_{v}\left(\frac{\partial^{2} u}{\partial z^{2}}\right)+M_{x}$

$\frac{D v}{D t}=-f u-g \frac{\partial \zeta}{\partial y}-\frac{g}{\rho_{0}} \int_{z^{\prime}=z}^{z^{\prime}=\zeta} \frac{\partial \rho}{\partial y} \mathrm{~d} z^{\prime}+v_{h}\left(\frac{\partial^{2} v}{\partial x^{2}}+\frac{\partial^{2} v}{\partial y^{2}}\right)+v_{v}\left(\frac{\partial^{2} v}{\partial z^{2}}\right)+M_{y}$

The added momentum terms can be expressed [21] as:

$M_{x}=-c_{\text {loss }-x} \frac{u^{2}}{\Delta x}$,

$M_{y}=-c_{\text {loss }-y} \frac{v^{2}}{\Delta y}$

where the coefficients $c_{\text {loss }-x}$ and $c_{\text {loss }-y}$ must be defined during the setup process of the model. In this case, the methodology defined in [24], which relates the $c_{\text {loss }}$ coefficients with the thrust coefficient exerted by a TEC, was used. Consequently, $c_{\text {loss }}$ coefficients can be defined [25] as:

$$
\begin{gathered}
c_{\text {loss }-x}=\frac{-2 \gamma_{x}}{\left(1+\sqrt{1-\gamma_{x}}\right)^{2}}, \\
c_{\text {loss }-y}=\frac{-2 \gamma_{y}}{\left(1+\sqrt{1-\gamma_{y}}\right)^{2}},
\end{gathered}
$$

$\gamma_{x}=\frac{C_{t} A_{t} \sin \theta}{n \Delta y \Delta z}$

$\gamma_{y}=\frac{C_{t} A_{t} \cos \theta}{n \Delta x \Delta z}$,

where $A_{t}$ is the total area occupied by the TEC, $\theta$ is the angle between the $x$ direction and the TEC axis (Fig. 2), $n$ is the number of vertical layers of the model occupied by the TEC, $C_{t}$ is the thrust coefficient of the TEC and $\Delta x$ and $\Delta y$ are the grid discretisation intervals in the $x$ and $y$ directions, respectively. Finally, it is important to point out that this approach presents some limitations related to the discretisation of the TEC, which are highlighted in [24]. As aresult, the Evopod Turbine [26], a floating horizontal axis tidal stream turbine, was used as a reference TEC for the present study. The main characteristics of the Evopod turbine are summarised in Table 4.

\subsection{Model implementation}

Four different hydrodynamic models were implemented in the area of study for the two stages proposed by the IEC-62600-201. With regard to Stage 1 , three models with the notation of S1_500, S1_250 and S1_125 were set up while, for Stage 2, a model with the notation of S2_25 was implemented.

Regarding the computational domain, Stage 1 models ( $\mathrm{S} 1 \_500$, S1_250 and S1_125) were implemented in 2D (i.e. depthaveraged) using Cartesian grids. Three different mesh sizes were used, with the aim of assessing the sensitivity of the grid size in terms of both accuracy and computational effort. The main characteristics of the computational grids are summarised in Table 3. Conversely, the S2_25 (i.e. layout design) was implemented in 3D using the $\sigma$-layer approach for the vertical discretisation. In this case, a uniform distribution of five $\sigma$-layers was prescribed, using a homogeneous thickness for all the layers corresponding with $20 \%$ of the local water depth. Regarding the horizontal discretisation, a Cartesian grid was also used, covering the area corresponding with

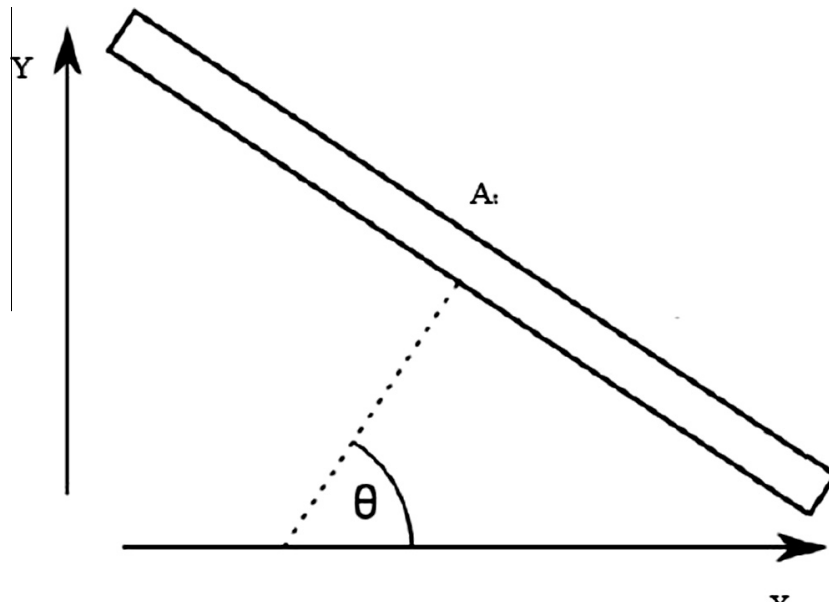

$\mathrm{X}$

Fig. 2. Schematic representation of a TEC for Delft3D implementation.

Table 3

Main grid characteristics of the models.

\begin{tabular}{ccc}
\hline & Grid size $(\mathrm{m})$ & Area covered $\left(\mathrm{km}^{2}\right)$ \\
\hline S1_500 & $500 \times 500$ & 36,000 \\
S1_250 & $250 \times 250$ & 25,000 \\
S1_125 & $125 \times 125$ & 7000 \\
S2_25 & $25 \times 25$ & 1000 \\
\hline
\end{tabular}


Table 4

Main characteristics of the evopod turbine.

\begin{tabular}{cc}
\hline Evopod turbine & \\
\hline Diameter $(\mathrm{m})$ & 20 \\
Cut-in velocity $\left(\mathrm{ms}^{-1}\right)$ & 0.7 \\
Cut-off velocity $\left(\mathrm{ms}^{-1}\right)$ & 4.4 \\
Rated velocity days $\left(\mathrm{ms}^{-1}\right)$ & 3.15 \\
Rated power $(\mathrm{kW})$ & 1680 \\
\hline
\end{tabular}

the tidal test site at the Fall of Warness, with a constant grid size of $25 \times 25 \mathrm{~m}$ (Table 3), which allows for a much more accurate representation of the shorelines and bathymetry. The bathymetric data for the region was obtained from the British Oceanographic Data Center (BODC) through the bathymetric data sets contained in the General Bathymetric Chart of the Oceans (GEBCO), which were interpolated onto the computational domains of the models by means of the Delft3D-QUICKIN toolbox. Fig. 3 shows the computational grids of the different models implemented for the present study.
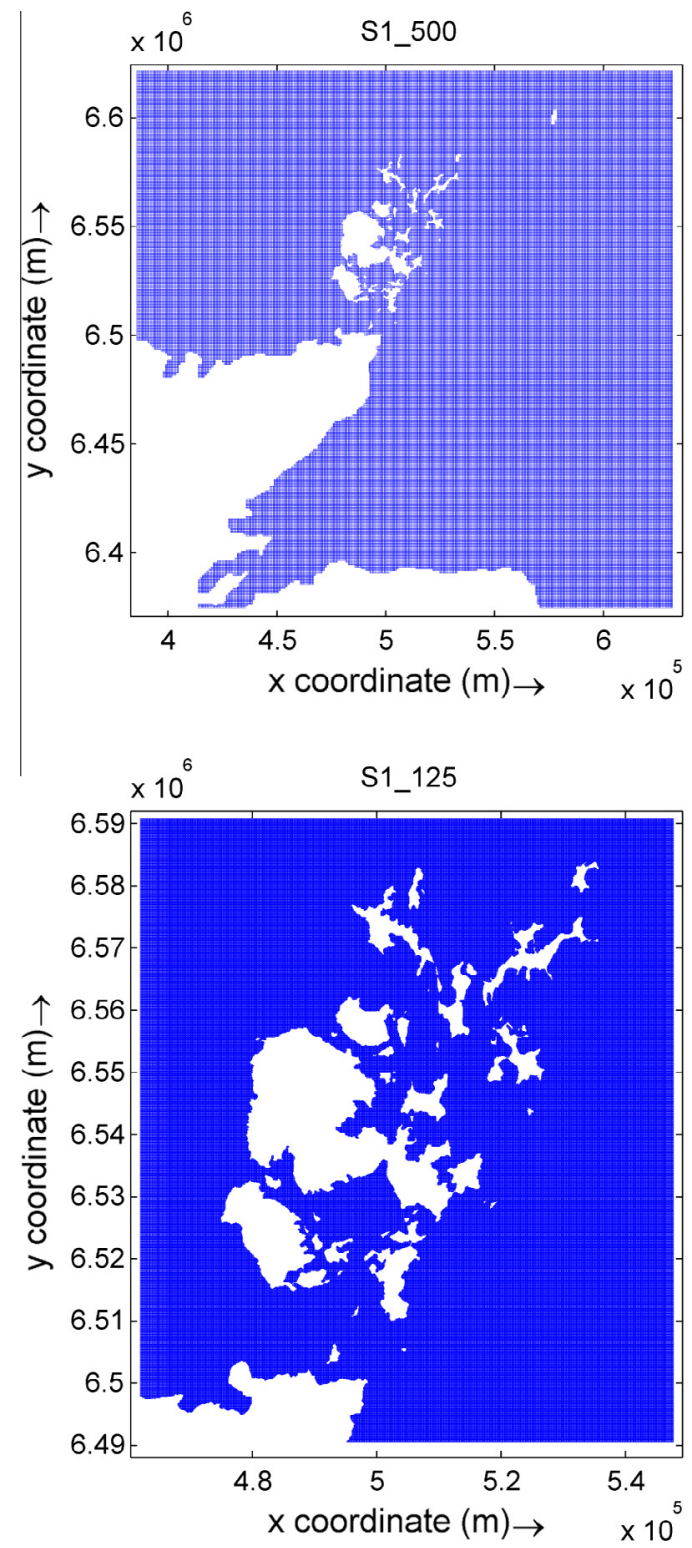

For all the models, only astronomical and Coriolis forcing were included in the model set-up. It was assumed that density gradients were too low to present a significant effect in the hydrodynamic behaviour of the region [27]. Furthermore, no significant river discharges in the vicinity of the Orkney Region were found and, therefore, no additional flow sources were included in the models.

With respect to the boundary conditions, two different approaches were used. For models S1_500 and S1_250, along the ocean boundary, a Dirichlet boundary condition was imposed, i.e. the sea level was prescribed as a function of time using the major tidal harmonics (M2, S2, N2, K2, K1, O1, P1, Q1, MF, MM, M4, MS4, MN4) obtained from the database TPXO 7.2, a global model of ocean tides that solves the Laplace equations using data from tide gauges and the TOPEX/Poseidon Satellite [28]. The number of harmonic constituents was chosen following [29], where a sensitivity analysis is carried out, drawing the conclusion that over 7 major constituents the $83 \%$ and $99 \%$ of the tidal amplitude and annual energy flux is accounted for. On the other hand, for models S1_125 and S2_25, the boundary conditions were obtained by
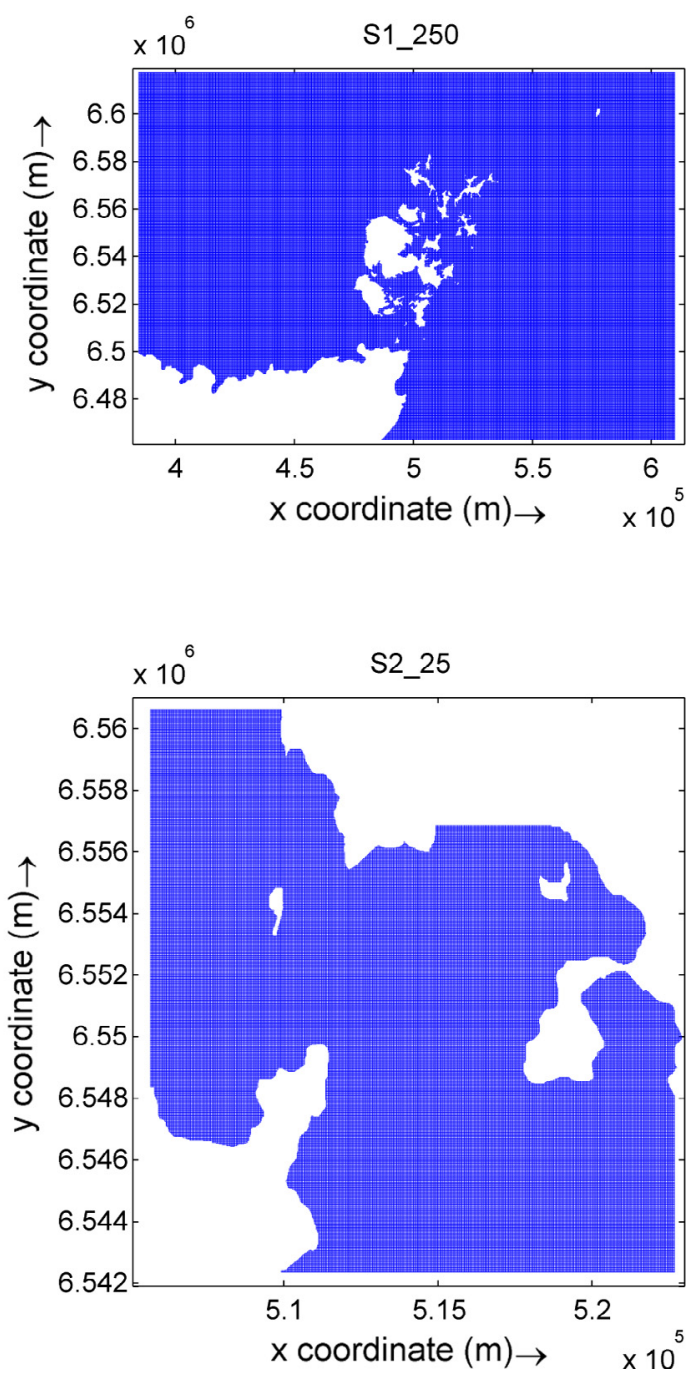

Fig. 3. Computational grids of the different models. 

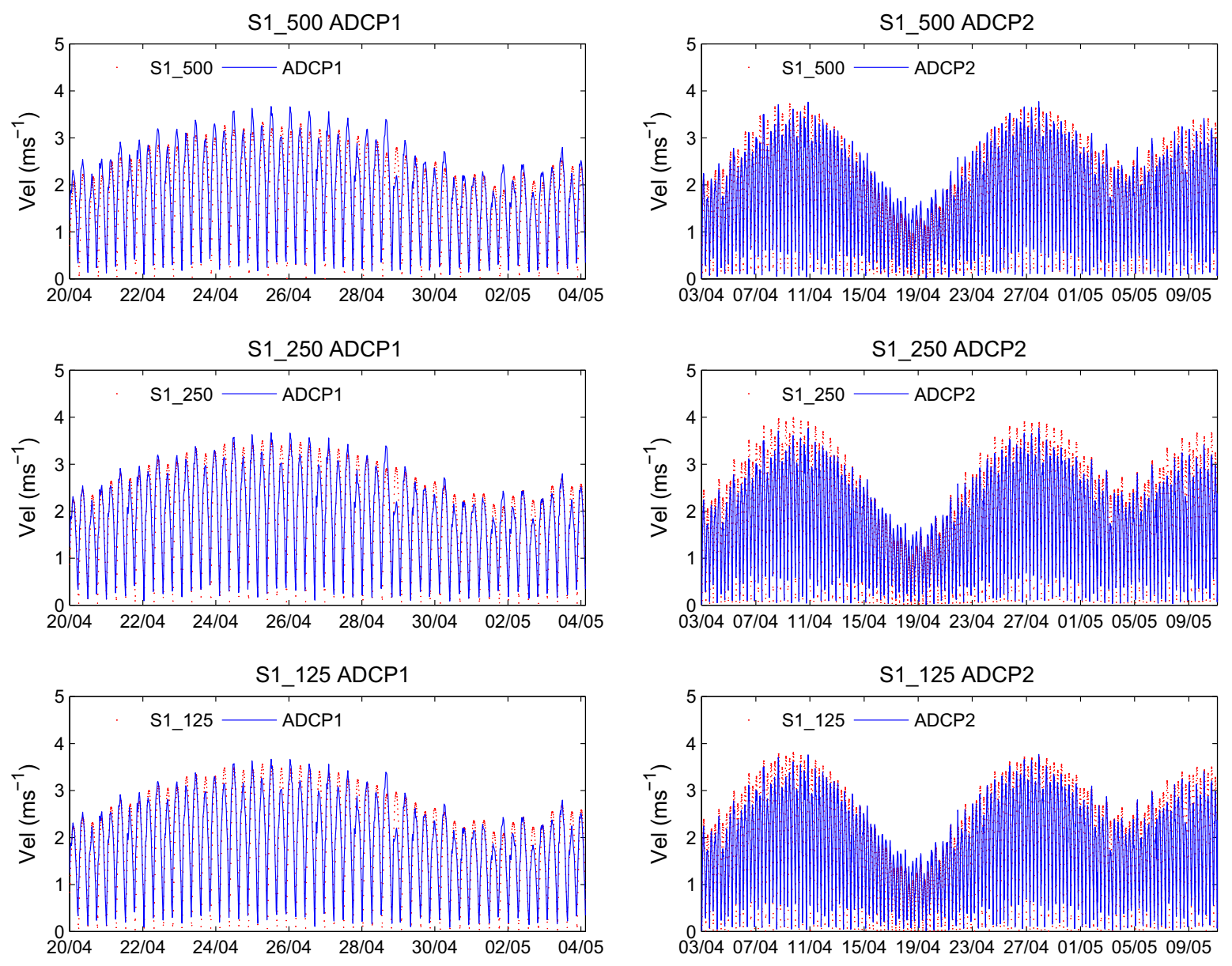

Fig. 4. Stage 1 model validation.

means of a nesting approach. To this end, models S1_125 and S2_25 were nested inside model S1_250 with the of generating high resolution time-series of the free surface elevation alongside the ocean boundaries of the nested models. Finally, at the land margins the boundary conditions were null velocity and free slip (zero shear stress).

\section{Results}

This section shows the main results obtained for the case study used in this investigation, focusing on: model validation (Section 3.1), TAEP estimation (Section 3.2), effects of TEC operation (Section 3.3), harmonic analysis for TAEP estimation (Section 3.4) and computational performance of the models (Section 3.5).

\subsection{Model validation}

In order to ensure that the models accurately predict the hydrodynamic conditions of the area of study, the models were validated by comparing the numerical results and measured data of the flow velocity. The field data were gathered by two Acoustic Doppler Current Profilers (ADCPs), deployed by the European Marine Energy Center (EMEC) at the Fall of Farness tidal test site (Fig. 1). ADCP1 covers the period from 20 April 2005 to 4 May 2005, whereas ADCP2 covers a period from 3 April 2009 to 11 May 2009.

For the models corresponding to Stage 1 (S1_500, S1_250 and S1_125), a good agreement was found between the time-series of the computed and measured magnitude of the flow velocity (Fig. 4), with only minor differences in the peak velocities in some tidal cycles. The corresponding statistical analysis is summarised in Table 5. As expected, the results of the validation improved with the degree of refinement of the models (higher grid resolution).

Regarding the Stage 2 model (S2_25), validation at different levels of the water column was carried out in order to ensure that the model accurately solves the 3D behaviour of the flow. Therefore, a comparison between the time-series of the computed and measured values of the flow velocity at the surface, mid-depth and bottom layers was carried out for ADCP1 (Fig. 5). The agreement in general is very good, with only minor differences in the maximum velocities of some tidal cycles and, again, the Stage 2 model shows an improvement in comparison with the Stage 1 models (Table 5), which appears to validate the IEC-62600-201 protocol.

Table 5

Root Mean Square Error (RMSE) and correlation coefficients $(R)$ of the model validation.

\begin{tabular}{ccc}
\hline & $R M S E_{A D C P 1}\left(\mathrm{~ms}^{-1}\right)$ & $R_{A D C P 1}$ \\
\hline S1_500 & 0.5699 & 0.7961 \\
S1_250 & 0.3912 & 0.9051 \\
S1_125 & 0.3903 & 0.9074 \\
S2_25 Surface Layer & 0.3935 & 0.9185 \\
S2_25 Middle Layer & 0.3982 & 0.9195 \\
S2_25 Bottom Layer & 0.3952 & 0.9166 \\
& $R M S E_{A D C P 2}\left(\mathrm{~ms}^{-1}\right)$ & $R_{A D C P 2}$ \\
\cline { 2 - 3 } S1_500 & 0.4723 & 0.8640 \\
S1_250 & 0.4069 & 0.9214 \\
S1_125 & 0.3614 & 0.9354 \\
\hline
\end{tabular}



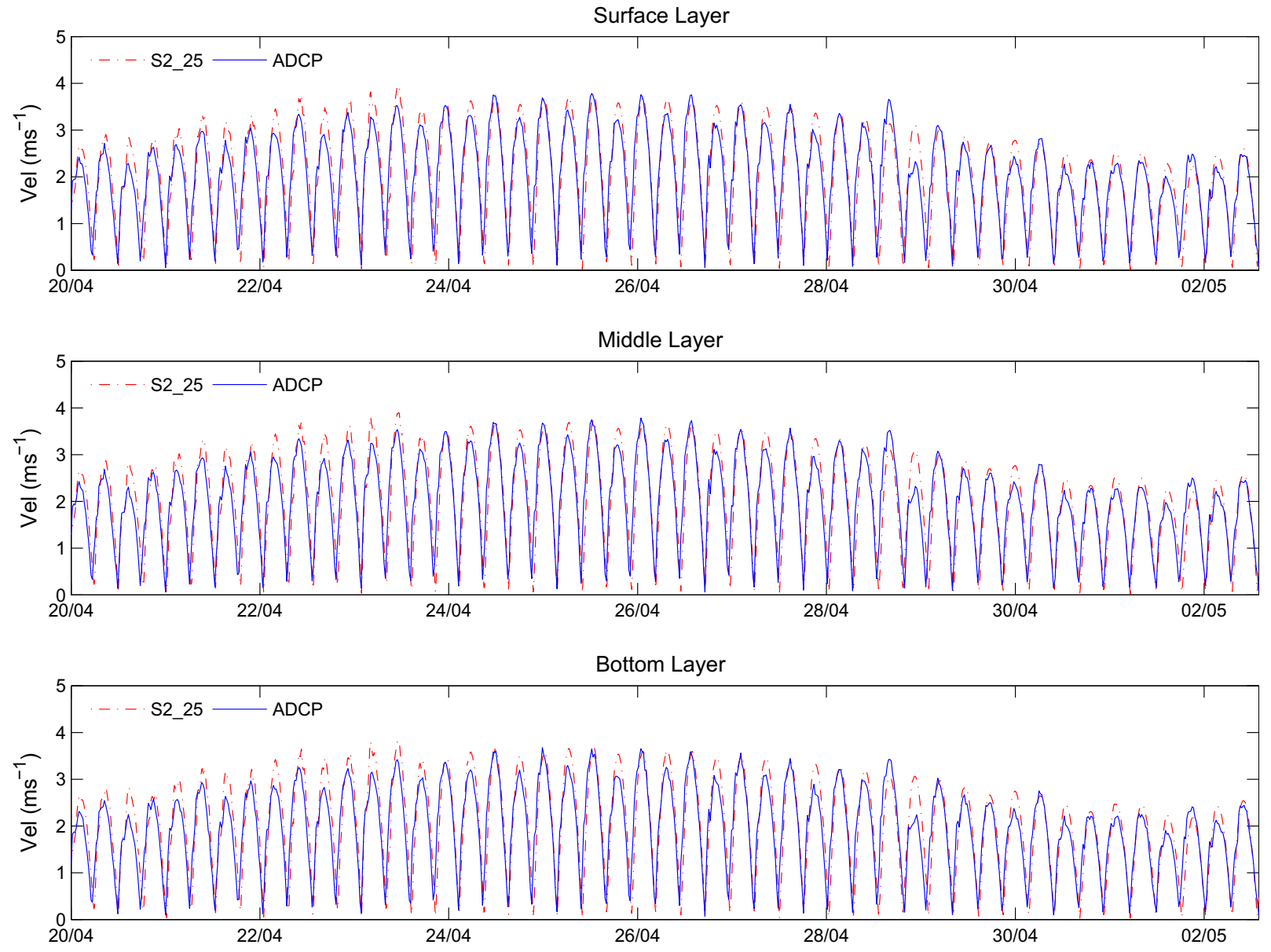

Fig. 5. Stage 2 model validation.

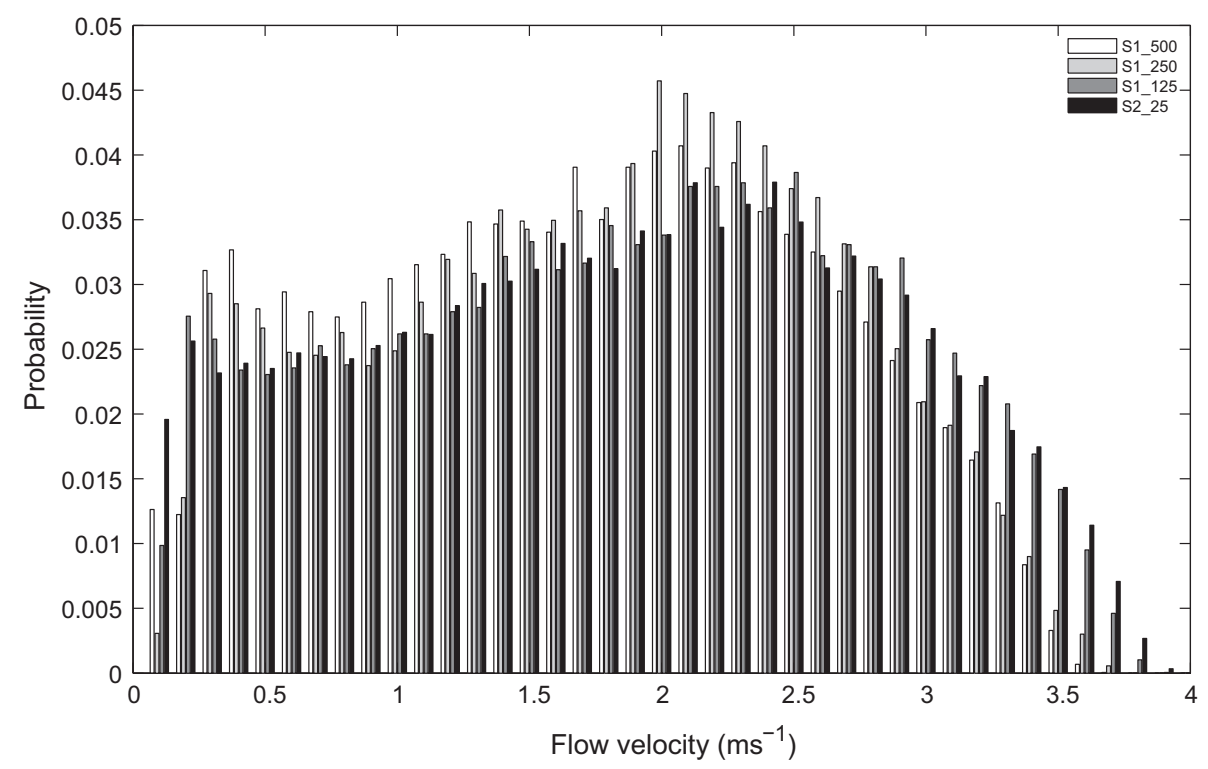

Fig. 6. Annual velocity distribution computed from the models.

\subsection{Individudal TEC Annual Energy Production (TAEP)}

As mentioned in Section 2.1, the main goal of the different modelling stages proposed by IEC-62600-201 is to determine the TAEP in a certain location. Accordingly, models S1_500, S1_250, S1_125 and S2_25 were used to estimate the TAEP and illustrate the variations among the different models in terms of energy estimation. For this purpose, the area corresponding to the location of ADCP1 was used as a case study (Fig. 1), while the Evopod Turbine was used as a reference TEC (Section 2.3). Finally, the models were run for an average year with the aim of obtaining the annual velocity distribution (Fig. 6) and the annual exceedance probability (Fig. 7). 


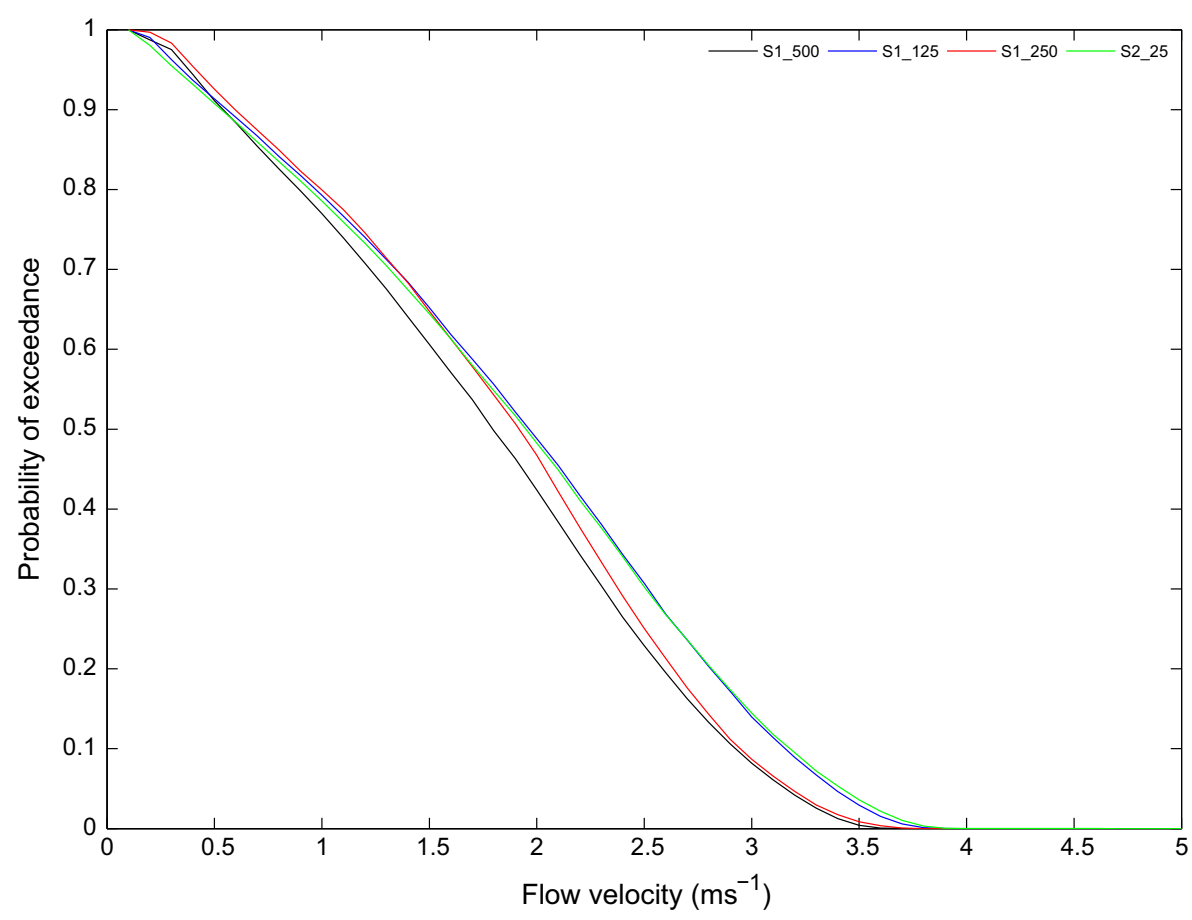

Fig. 7. Annual exceedance probability computed from the models.

Overall, it can be observed that the area of study presents a significant resource with the presence of tidal peak velocities exceeding $4 \mathrm{~ms}^{-1}$, and with probabilities of exceedance in the order of 0.5 for tidal velocities larger than $2.0 \mathrm{~ms}^{-1}$. In addition, it can be observed that there are significant differences among the results produced by the different models. For instance, models S1_500 and S1_250 appear not to be able to properly estimate the exceedance probability for flow velocities higher than $2.0 \mathrm{~ms}^{-1}$, which may translate into an underestimation of the TAEP. Conversely, models S1_125 and S2_25 present a very similar behaviour for both the annual velocity distribution and the annual exceedance probability.

Finally, the TAEP was computed for the different models following the procedure proposed by IEC-62600-201 (Eq. (1)). As expected, the results obtained show that models S1_500 and S1_250 underestimate the TAEP in comparison with models S1_125 and S2_25 (Table 6). This translates into differences up to $19.10 \%$ in comparison with S2_25, which was used as a reference, since it offers the best validation results.

\subsection{Effects of TEC operation in TAEP estimation}

With the purpose of validating the methodology proposed by IEC-62600-201, regarding the necessity of including the TEC operation in the hydrodynamic modelling for tidal projects with a capacity larger than $10 \mathrm{MW}$ and/or $2 \%$ of the theoretical energy resource due to potential disturbances on the available tidal

Table 6

TAEP and differences among the different models.

\begin{tabular}{ccc}
\hline & TAEP $(\mathrm{GW} \mathrm{h})$ & \% Dif-S2_25 \\
\hline S1_500 & 3.81 & 19.10 \\
S1_250 & 4.11 & 10.26 \\
S1_125 & 4.56 & 0.56 \\
S2_25 & 4.53 & - \\
\hline
\end{tabular}

resource, a tidal farm of 7 Evopod Turbines with an installed power capacity of $11.76 \mathrm{MW}$ was proposed for the Fall of Warness tidal test site (Fig. 8). This area presents an outstanding tidal resource, with homogeneous flow velocities exceeding $3.5 \mathrm{~ms}^{-1}$ and $2.2 \mathrm{~ms}^{-1}$ at mid-ebb and mid-flood of a mean-spring tide, respectively (Fig. 9). Following [30], a triangular distribution for the tidal turbines was chosen, with the rows separated $100 \mathrm{~m}$ (fivediameters) from each other (in the NW-SE direction) and a lateral separation of $60 \mathrm{~m}$ (three-diameters) among the turbines of the same row (in the SW-NE direction) (Fig. 8).

Once the location and configuration of the tidal farm were defined, the S2_25 model was run with and without considering the operation of the tidal turbines, energy extraction and baseline cases, respectively, for a period corresponding with a complete spring-neap tidal cycle (i.e. 14.8 days). The operation of the Evopod turbines in Delft3D was modelled according to the methodology presented in Section 2.3, considering a constant value of the thrust coefficient $C_{t}$ of 0.85 [24]. The effects on the tidal flow (magnitude and direction) were investigated by computing the differences in the velocities between the energy extraction and baseline cases. Fig. 10 shows the differences in the tidal flow between the energy extraction and baseline cases at mid-ebb and mid-flood of a mean spring tide. Overall, it can be observed that there is a velocity reduction upstream, but specially downstream (up to $0.3 \mathrm{~ms}^{-1}$ ), of the tidal farm, which extends hundred of metres downstream of the tidal farm. With respect to each individual turbine, a similar pattern can be observed with the additional feature that the flow is diverted and concentrated at both sides of the turbines, resulting in an increase of the inter-device tidal velocities (up to $0.1 \mathrm{~ms}^{-1}$ ). Finally, in order to quantify these alterations in terms of power production, the energy generated for each individual turbine during the spring-neap tidal cycle was computed for the baseline and energy extraction cases, respectively. With reference to Table 7 , the layout proposed for the tidal farm results in a destructive effect (i.e. reduction of the power production), since every single turbine shows a reduction in the generated energy, which ranges from $5.40 \%$ (T5) to $12.63 \%$ (T1). 

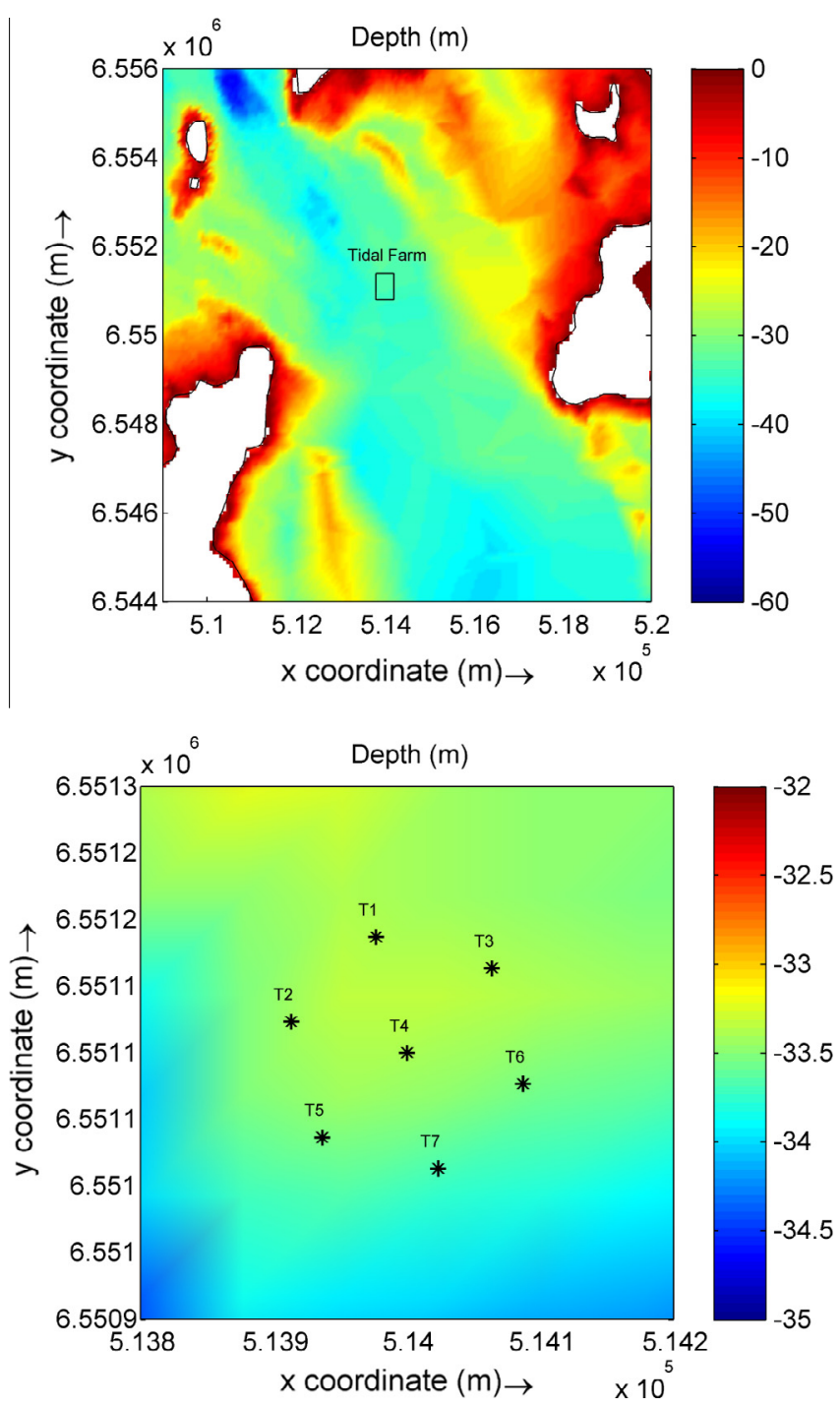

Fig. 8. Location and layout of the proposed tidal farm.

\subsection{TAEP estimation: harmonic analysis vs hydrodynamic modelling}

As mentioned in Section 2.1, IEC-62600-201 proposes a methodology with the purpose of estimating the TAEP using harmonic analysis. The main advantage of a harmonic analysis is that no significant computational cost is required. However, the time series of recorded data has to be large enough in order to obtain a reliable prediction of the tidal velocities [29]. To test this condition, a comparison between the harmonic analysis prediction and the results obtained by means of hydrodynamic modelling was carried out. In this case, the results obtained from model S2_25 were used as a reference, since it is the model that offers the most precise validation results.

The T_tide toolbox [31] was used to extract the harmonic constituents of the tidal velocity from ADCPs 1 and 2. Then, the same harmonic constituents used to force the models (M2, S2, N2, K2, K1, O1, P1, Q1, MF, MM, M4, MS4, MN4) were employed to reconstruct the annual time-series of the tidal velocity in the locations corresponding with ADCPs 1 and 2, respectively (Table 8). Finally, the same methodology used in Section 3.2 was applied to determine the annual velocity distribution (Figs. 11 and 13), the annual exceedance probability (Figs. 12 and 14) and the estimated TAEP (Table 9).
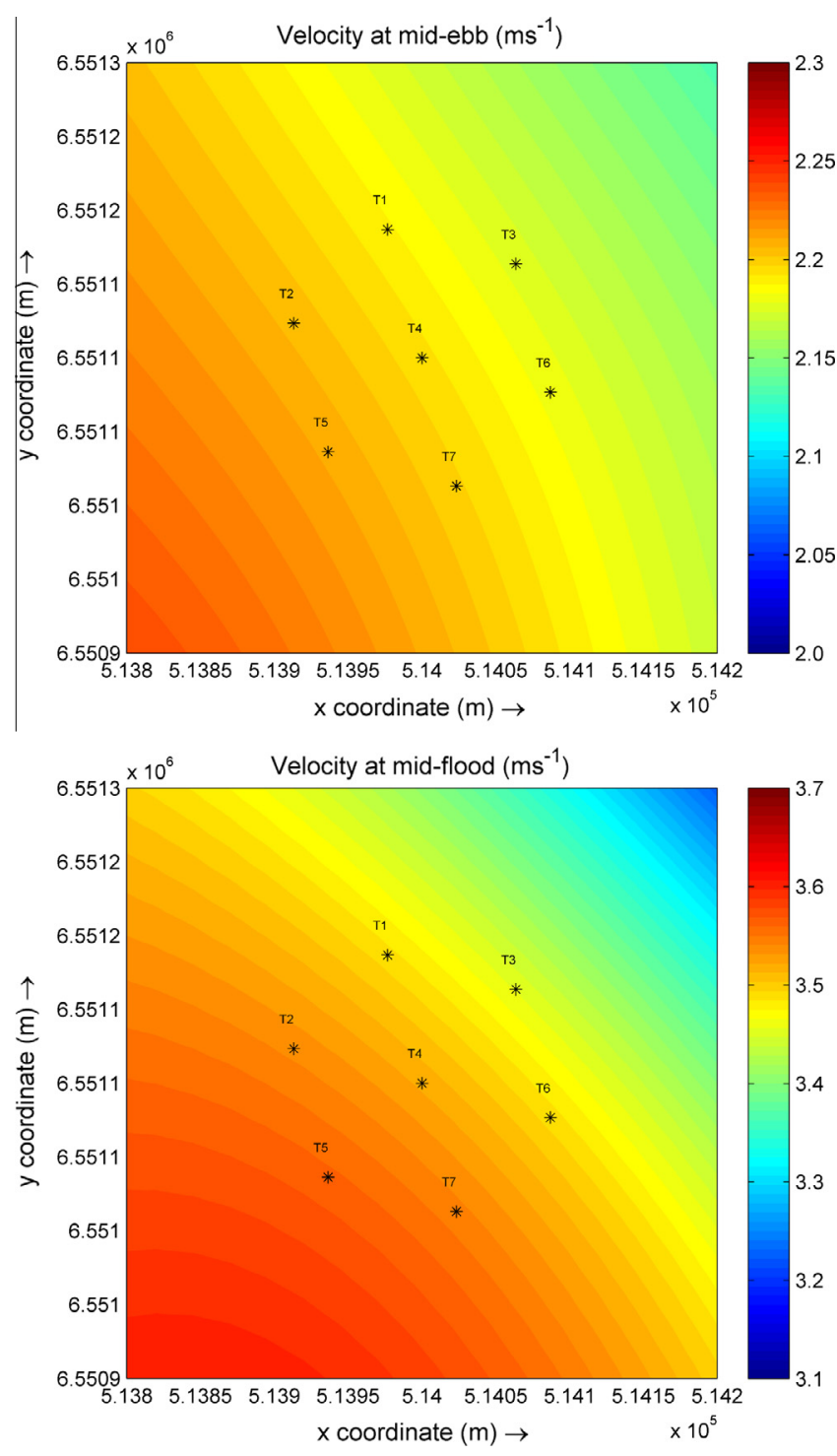

Fig. 9. Mid-ebb and mid-flood velocities at the proposed tidal farm.

As expected, the results obtained from harmonic analysis of ADCP1 show a noticeable disagreement with model S2_25. The harmonic analysis seems to overestimate the occurence of tidal velocities in the range of $2.25-2.75 \mathrm{~ms}^{-1}$ and not to be able to predict tidal velocities higher than $3 \mathrm{~ms}^{-1}$. This can be explained by the fact that ADCP1 only presents a record length of 14 days, allowing only for the extraction of the constituents (M2,K1,O1, M4), which results in a significant misrepresentation of the reconstructed time-series of tidal velocity. On the other hand, the results obtained from ADCP2 show a good agreement with model S2_25. In this case, the length record of ADCP2 covers 38 days, which allows for the extraction of all the harmonic constituents used to force model S2_25. In addition, this length record also decreases the errors in the estimation of the harmonic constituents [29].

Finally, Table 9 shows a comparison between the TAEP estimated by the harmonic analysis and the hydrodynamic modelling approaches. The results obtained show that differences between both methods are less than $10 \%$, which could prove that the harmonic analysis could be used as a rapid initial estimation of the TAEP for a certain location. 

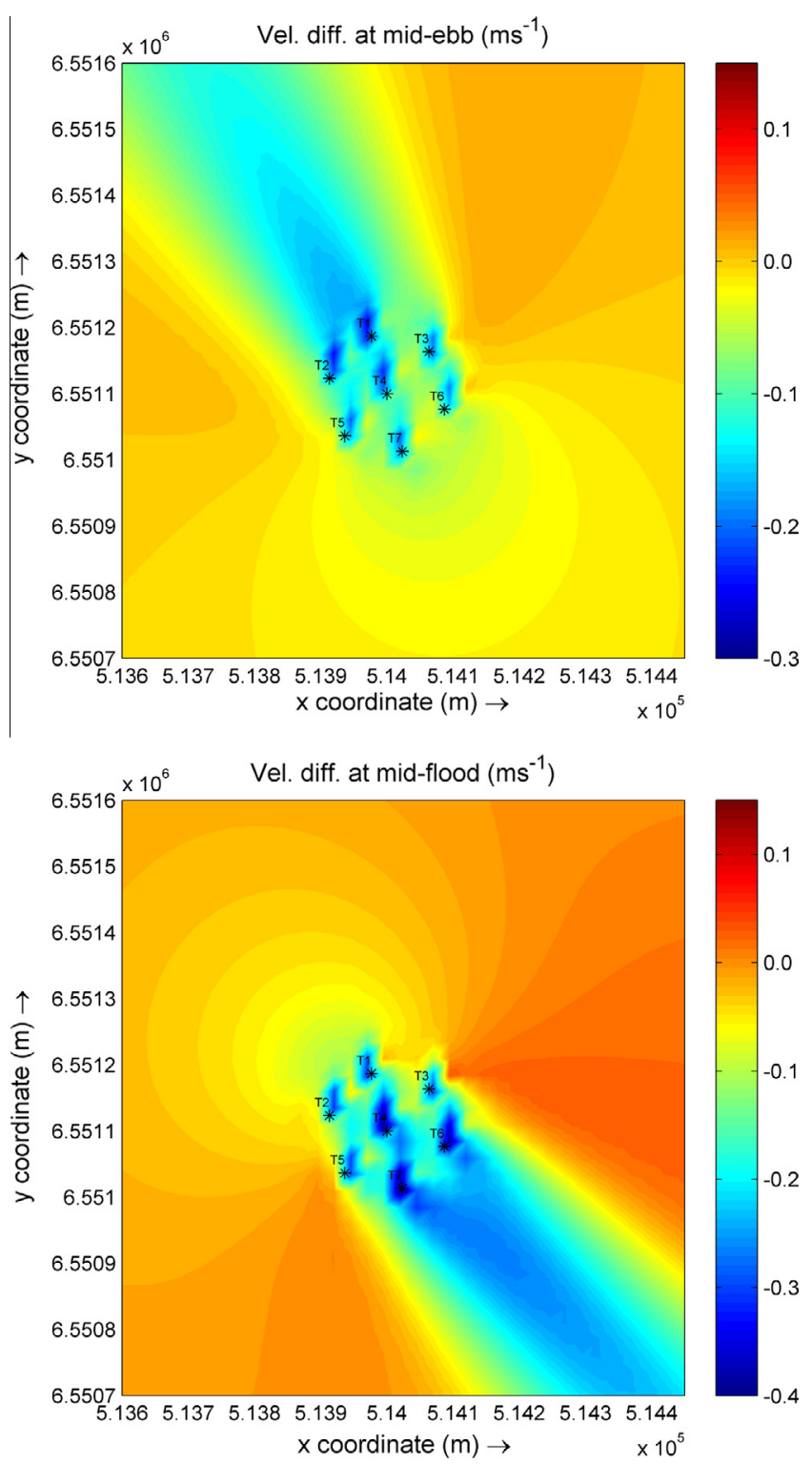

Fig. 10. Velocity differences at Mid-ebb and mid-flood between the baseline and energy extraction cases.

\subsection{Computational performance of the models}

The models were also compared from a computational standpoint. The computational tasks were carried out in a HPC facility, the Irish Centre for High-End Computing (ICHEC) using $24 \times 2.4 \mathrm{GHz}$ Intel Xeon E5-2695 cores. Table 10 summarises the

Table 7

Energy production of each individual turbine for the baseline and energy extraction cases.

\begin{tabular}{cccc}
\hline & $\begin{array}{c}\text { Baseline case energy } \\
\text { prod. }(\mathrm{MW} \mathrm{h})\end{array}$ & $\begin{array}{c}\text { Energy extraction case } \\
\text { energy prod. }(\mathrm{MW} \mathrm{h})\end{array}$ & $\begin{array}{c}\text { Diff. cases base- } \\
\text { energy ext. }(\%)\end{array}$ \\
\hline T1 & 94.88 & 84.25 & 12.63 \\
T2 & 97.77 & 89.05 & 9.79 \\
T3 & 90.90 & 83.64 & 8.68 \\
T4 & 95.61 & 84.77 & 12.79 \\
T5 & 98.70 & 93.64 & 5.40 \\
T6 & 92.23 & 83.32 & 10.69 \\
T7 & 96.76 & 86.80 & 11.48 \\
\hline
\end{tabular}

CPU hours required for each model. It can be observed that the computational effort required by S2_25 (the stage2 model) is significantly higher than that required for the Stage 1 models, which is mainly due to the higher horizontal mesh resolution and the 3D vertical discretisation. Finally, Fig. 15 shows the relationship between the accuracy of the models (in terms of Correlation Coefficient, $R$ and Root Mean Square Error, RMSE) and the computational effort. As can be observed, the accuracy of the model improves dramatically from S1_500 to S1_250 (grid resolution of $500 \times 500 \mathrm{~m}$ vs $250 \times 250 \mathrm{~m}$ ); however, the improvement felt from S1_250 to S1_125 and S2_25 is not so remarkable, while the required computational time is 14 times higher for S2_25.

\section{Discussion}

This section aims to offer some feedback on the IEC-62600-201, with respect to the main aspects tackled in this investigation: the model setup process and the methodology proposed for the quantification of the TEC Annual Energy Prodcution (TAEP).

Overall, the methodology proposed by IEC-62600-201 for the modelling setup process appears to perform well for the present case study, proving that the increase in the degree of refinement of the different model stages (Feasibility and Layout design) reduces the level of uncertainty in the estimation of the tidal flow and, therefore, in the TAEP quantification. Regarding the main recommendations for the modelling setup process (computational domain, boundary conditions and physical processes to considered) proposed by IEC-62600-201, they appear to be coherent and in good agreement for the objectives of the two stages of resource assessment set by IEC-62600-201. The results obtained in the present study prove that no major changes in the model setup process are required. However, regarding the horizontal resolution of the computational domain some interesting insight was achieved. As can be observed in Fig. 15, the results, in terms of accuracy, improved dramatically from S1_500 to S1_250 (grid resolution of $500 \times 500 \mathrm{~m}$ vs $250 \times 250 \mathrm{~m}$ ); however, from S1_250 to S1_125 and S2_25 (grid resolutions of $125 \times 125 \mathrm{~m}$ and $25 \times 25 \mathrm{~m}$, respectively) the improvement felt is almost negligible, especially in the case of S1_125 and S2_25. On the other hand, the computational effort increased considerably as the grid resolution was finer, especially for the case of S2_25. This fact should not be considered of minor importance, especially in attempting to find the right balance between the accuracy and the computational effort required by the model, since high-resolution models, such as S2_25 or S1_125, require higher computational times (Table 10), whereas the level of accuracy provided is only slightly better than S1_250. Therefore, taking all these apects into consideration, the requirements for the Stage 2 model setup regarding the minimum grid resolution should potentially be revisited for future editions of IEC-62600-201.

With respect to the methodology developed by IEC-62600-201 for the TAEP quantification, the results obtained for the present work prove that the methodology proposed is robust and coherent. However, there are some issues that must be addressed in more detail, especially those related to the modelling of the TEC operation within a hydrodynamic model. The results obtained in the present case study clearly show that there is an overestimation of TAEP (up to $12 \%$ ) for the case in which the model was run without taking into account the TEC operation and, therefore, the presence of TECs must be taken into account for large tidal energy projects. Nevertheless, when modelling the operation of a TEC within a hydrodynamic model, different methodologies can be found in the literature, with most of them presenting significant limitations. In the present study, the momentum sink approach was used in Delft3D-Flow via the so-called Porous plate tool, whose main 
Table 8

Harmonic constituents of the tidal flow velocities extracted from ADCPs 1 and 2 .

\begin{tabular}{|c|c|c|c|c|c|}
\hline ADCP1 & Frequency $(\mathrm{Hz})$ & Major $\left(\mathrm{ms}^{-1}\right)$ & Minor $\left(\mathrm{ms}^{-1}\right)$ & Inclination $\left(^{\circ}\right)$ & Phase $\left(^{\circ}\right)$ \\
\hline M2 & 0.0805 & 2.722 & 0.133 & 121.52 & 49.15 \\
\hline K1 & 0.0418 & 0.076 & 0.003 & 132.05 & 292.68 \\
\hline 01 & 0.0387 & 0.080 & 0.005 & 124.39 & 83.99 \\
\hline M4 & 0.1610 & 0.187 & 0.001 & 44.08 & 287.00 \\
\hline ADCP2 & Frequency $(\mathrm{Hz})$ & Major $\left(\mathrm{ms}^{-1}\right)$ & Minor $\left(\mathrm{ms}^{-1}\right)$ & Inclination $\left(^{\circ}\right)$ & Phase $\left({ }^{\circ}\right)$ \\
\hline M2 & 0.0805 & 2.586 & 0.144 & 108.49 & 59.21 \\
\hline $\mathrm{S} 2$ & 0.0833 & 0.924 & 0.031 & 107.46 & 73.39 \\
\hline N2 & 0.0789 & 0.351 & 0.013 & 105.86 & 34.22 \\
\hline $\mathrm{K} 1$ & 0.0418 & 0.094 & 0.007 & 104.74 & 261.70 \\
\hline 01 & 0.0387 & 0.104 & 0.005 & 107.27 & 108.47 \\
\hline Q1 & 0.0372 & 0.029 & 0.002 & 107.86 & 50.01 \\
\hline MM & 0.0015 & 0.035 & 0.003 & 155.18 & 220.45 \\
\hline M4 & 0.1610 & 0.124 & 0.059 & 122.95 & 310.73 \\
\hline MS4 & 0.1638 & 0.064 & 0.038 & 102.45 & 271.24 \\
\hline MN4 & 0.1595 & 0.027 & 0.001 & 110.60 & 269.70 \\
\hline
\end{tabular}

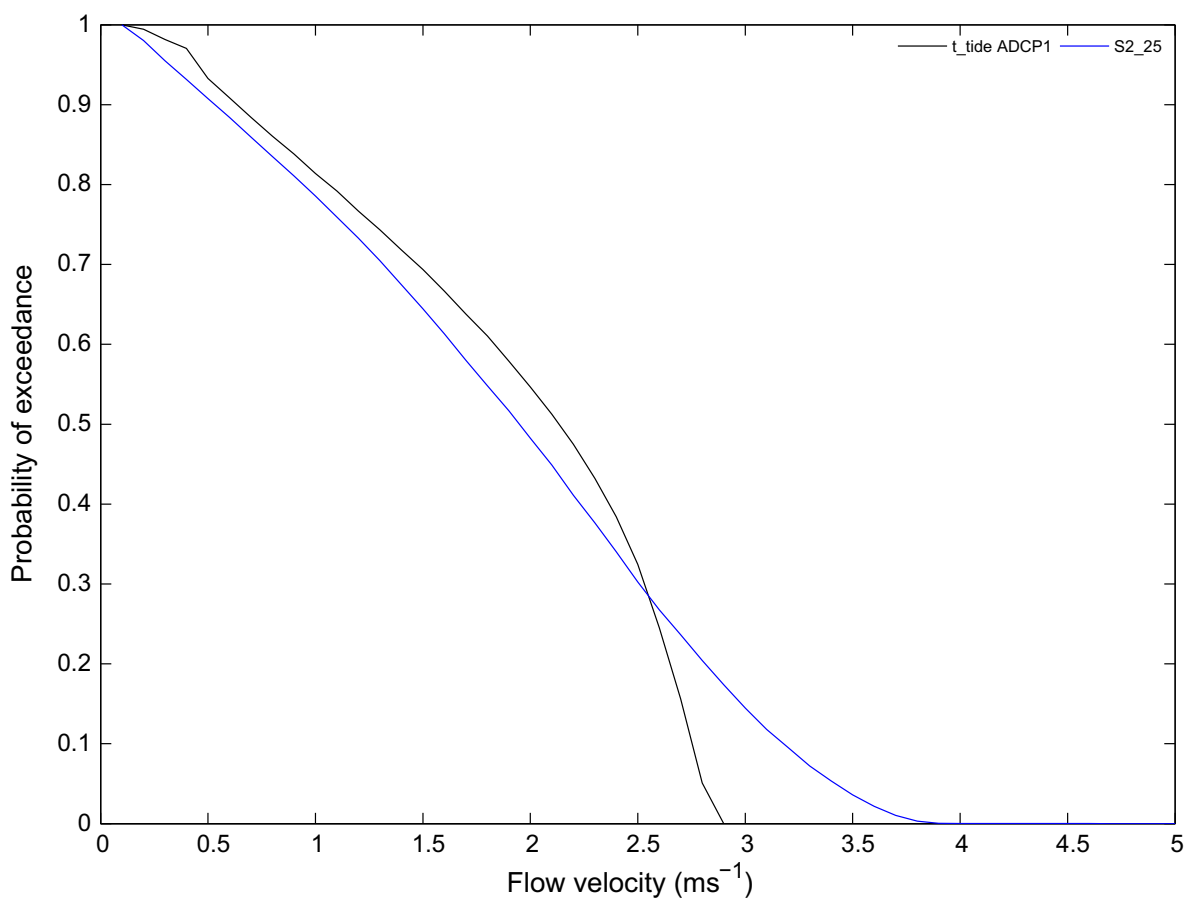

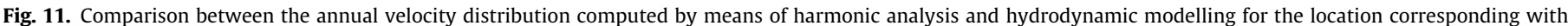
ADCP1.

limitation is the assumption of a constant thrust coefficient $\left(C_{t}\right)$ to cover the complete turbine operational space. Therefore, taking all these facts into consideration, IEC-62600-201 should clearly state which of the approaches present in the literature should be used for modelling TEC operation, or to develop its own standard methodology, with the aim of avoiding misrepresentations in the TAEP estimation, which may jeopardise the initial viability of tidal stream projects.

Regarding the procedure proposed by IEC-62600-201 to estimate the TAEP throughout harmonic analysis, the results presented in Section 3.4 show that similar results to the hydrodynamic modelling may be obtained if the measured record length is large enough (in this case 38 days were used). Despite the fact that this approach could save a huge amount of computational effort, there are some aspects that must be considered carefully. For instance, this approach could lead to misrepresentations in the estimated TAEP in regions where non-tidal and highly seasonal factors such as wind, waves or river discharges play an important role in the hydrodynamic behaviour of the tidal flow. In addition, IEC-62600-201 should specifically set the length of the measured record for the cases in which the harmonic analysis is carried out based on field measurements since, as shown in Figs. 12 and 14, it appears to play an important role in the correct estimation of the TAEP. In addition, the harmonic approach can only be applied to a specific point in the area of interest and, therefore, the local effects on the tidal flows due to the TEC operation cannot be accounted for. Taking all these facts into account, the authors of the present study would recommend that the use of the harmonic analysis is restricted to Stage 1 tidal projects. 


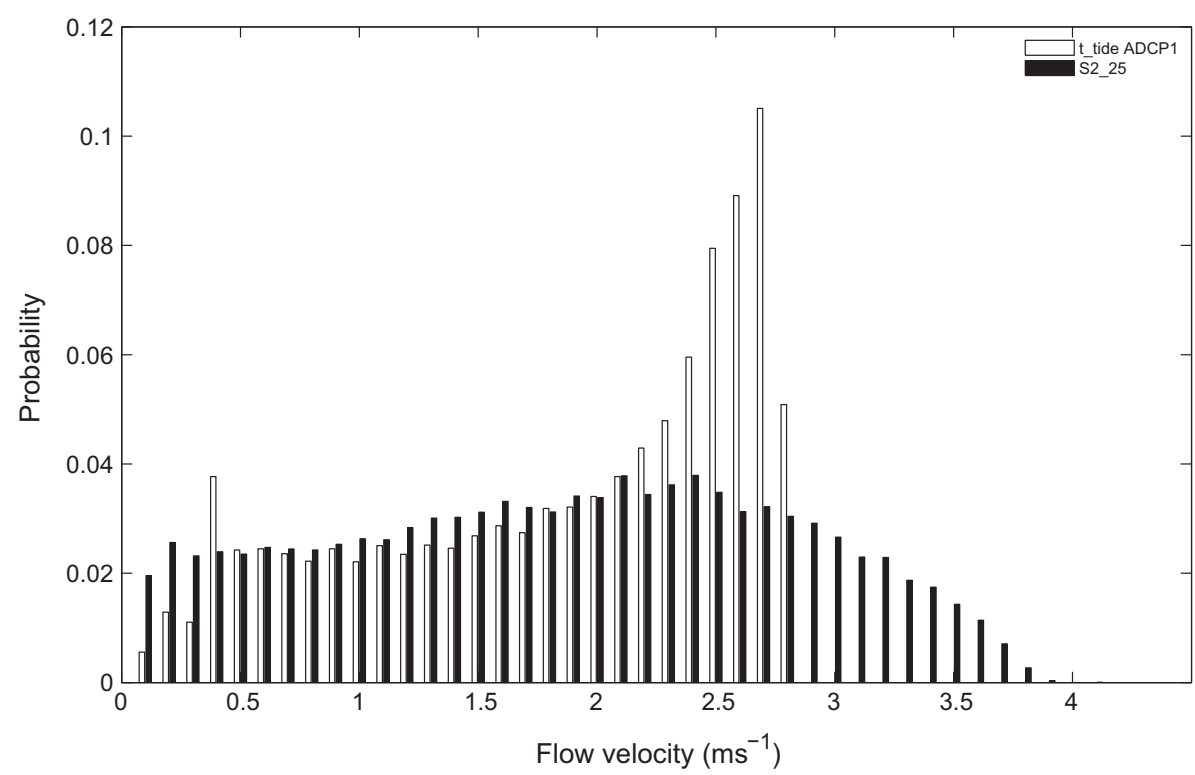

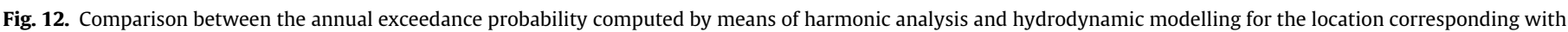
ADCP1.

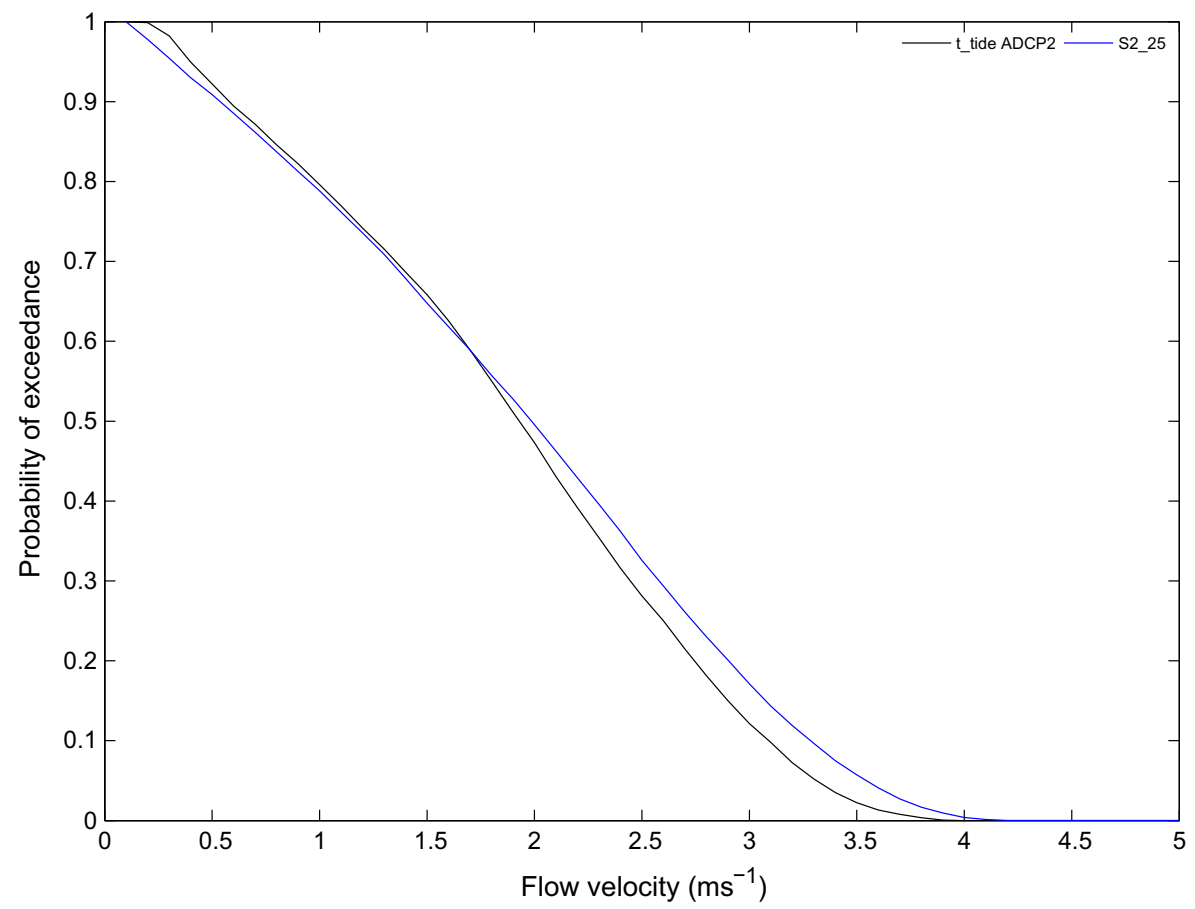

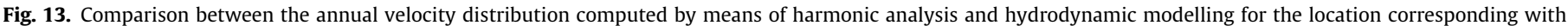
ADCP2.

Finally, it is important to point out that all these recommendations are based on the results obtained for the present study and, therefore, they should be supported by other works. For this purpose, more studies like the present one should be carried out for different locations subject to different tidal ranges and conditions with the purpose of offering to IEC-62600-201 a broader feedback for future editions. So far, only a few tidal resource assessments based on IEC-62600-201 are available in the literature [29]. 


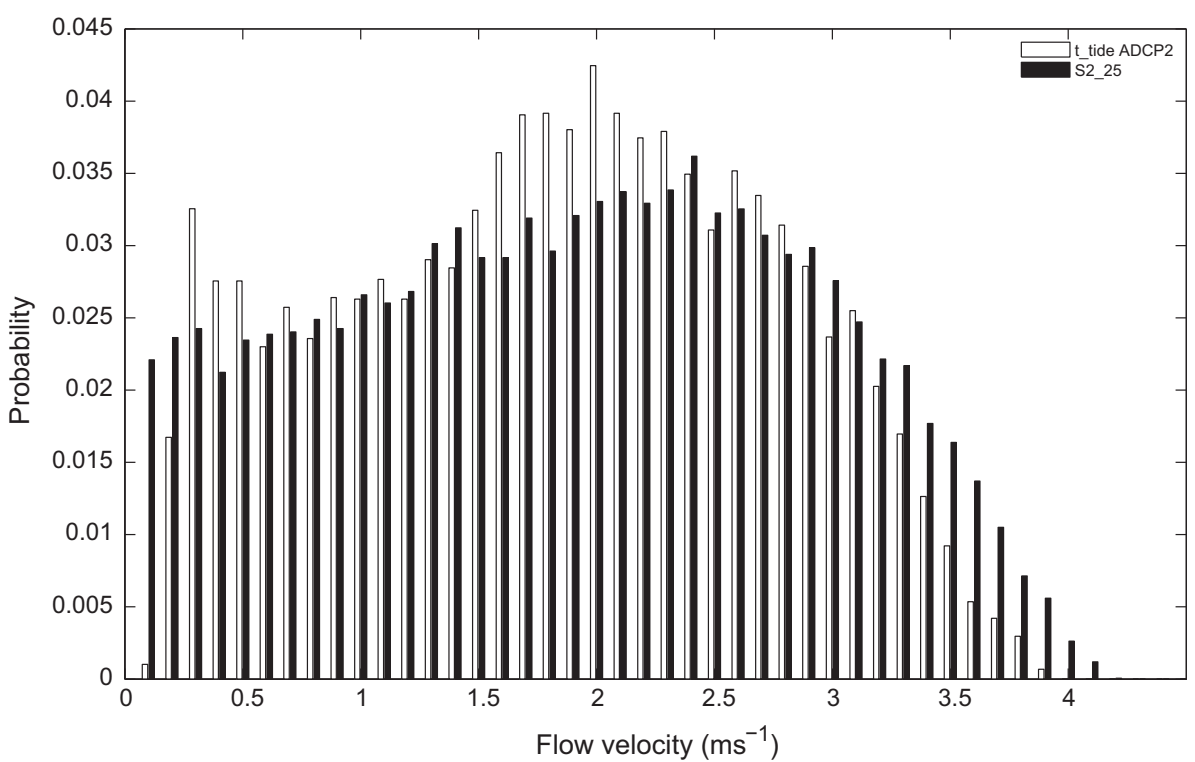

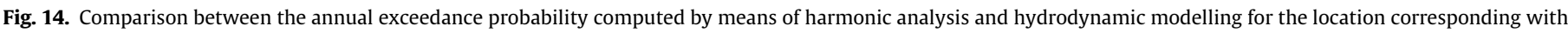
ADCP2.

Table 9

Differences in TAEP estimation between harmonic analysis and hydrodynamic modelling.

\begin{tabular}{ccc}
\hline & ADCP1 & ADCP2 \\
\hline TAEP $_{t_{-} \text {tide }}(\mathrm{GW} \mathrm{h})$ & 4.09 & 4.49 \\
TAEP $_{S 2 \text { 25 }}(\mathrm{GW} \mathrm{h})$ & 4.53 & 4.82 \\
Dif $(\%)$ & 9.71 & 6.80 \\
\hline
\end{tabular}

Table 10

Computational times of the different models.

\begin{tabular}{cc}
\hline & CPU time (hr) \\
\hline S1_500 & 3.37 \\
S1_250 & 4.83 \\
S1_125 & 6.22 \\
S2_25 & 88.60 \\
\hline
\end{tabular}

\section{Conclusions}

In recent years, the interest in harvesting the tidal stream energy resource has translated into a large number of tidal stream resource assessments. However, different approaches have been considered, utilising a variety of time scales, effects derived from the wave-current interactions and the methodologies used for the representation of TEC operation. Consequently, the IEC has developed a methodology (IEC-62600-201) with the aim of standardising tidal stream resource characterisation. The aim of this paper is to explore the utility of the IEC-62600-201 by means of a case study, focusing on the main aspects of the modelling setup process and TAEP estimation.

Overall, IEC-62600-201 has proven to be a robust and coherent methodology, which offers a relatively clear set of recommendations and rules to carry out a precise tidal stream resource

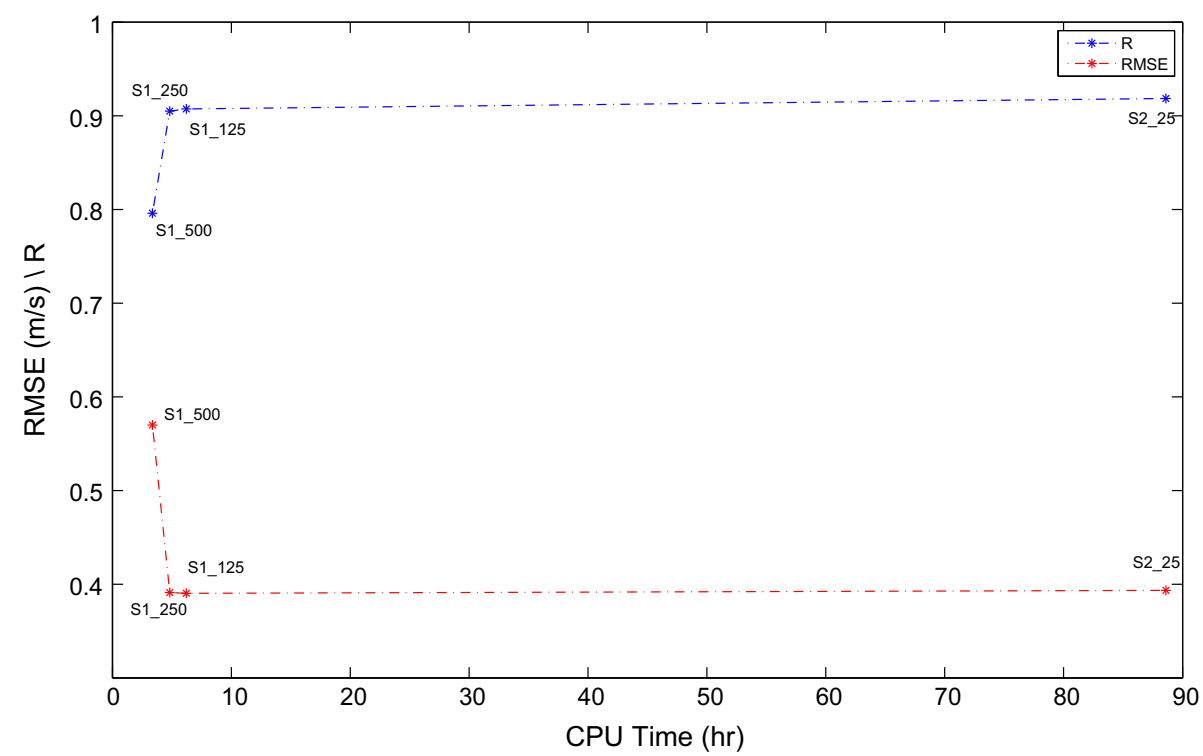

Fig. 15. Accuracy of the models (R,RMSE) vs computational times (CPU hours). 
characterisation. Regarding the modelling setup process, the results obtained show that the grid resolution plays a limited role on the accuracy of the models but, on the other hand, the impact on the computational times is quite significant. For these reasons, the minimum grid resolution required for the Stage 2 models could be increased for future editions of the standard. From the point of view of TAEP estimation, the main issue that may be addressed for future editions of IEC-62600-201 is to define a standard methodology to simulate TEC operation within a hydrodynamic model, which is essential to obtain an accurate representation of the behaviour of the tidal flow in the vicinity of a tidal farm and, therefore, a good estimation of the TAEP. In addition, TAEP estimation using harmonic analysis has proven to be a good methodology for an initial estimation of the tidal resource, but should be mainly considered for use in Stage 1 tidal projects in which non-tidal and highly seasonal factors (waves, wind and fresh water discharges) are not relevant in the region of interest. Finally, it is important to point out that these recommendations should be corroborated with feedback from other studies of the same nature as the present one.

In summary, this work explores the main characteristics of the IEC-62600-201 offering some feedback for future editions, although alternative aspects that may lead to improvements in IEC-62600-201, such as the tidal resource characterisation by means of machine learning and the effects of wave-current interactions, are outside the scope of this work and will be dealt with as a continuation of this research.

\section{Acknowledgments}

This research is based upon works supported by Science Foundation of Ireland under Grant No. 12/RC/2302 for the Marine Renewable Ireland (MAREI) centre. During this work, V. Ramos was supported by the I2C postdoctoral grant ED481B 2014/059-0 (Plan Galego de Investigacion Innovacion e Crecemento 20112015) of the Xunta de Galicia (Spain). Its authors are also indebted to the European Marine Energy Centre (EMEC) for its contribution with the ADCP data and the Irish Centre for High-End Computing (ICHEC) for its cooperation in the computational tasks.

\section{References}

[1] E. Directive. Directive $2001 / 77 /$ ec of the european parliament and of the council of 27 september 2001 on the promotion of electricity produced from renewable energy sources in the internal electricity market. Official J Eur Commun L 283; 2001.

[2] Bahaj AS. Generating electricity from the oceans. Renew Sustain Energy Rev 2011;15(7):3399-416. http://dx.doi.org/10.1016/i.rser.2011.04.032.

[3] Rourke FO, Boyle F, Reynolds A. Renewable energy resources and technologies applicable to Ireland. Renew Sustain Energy Rev 2009;13(8):1975-84. http:/l dx.doi.org/10.1016/i.rser.2009.01.014.

[4] Blunden L, Bahaj A. Initial evaluation of tidal stream energy resources at Portland Bill, UK. Renew Energy 2006;31(2):121-32. http://dx.doi.org/ 10.1016/i.renene.2005.08.016. Marine Energy.

[5] Rourke Fergal O, Boyle Fergal, Reynolds Anthony. Tidal energy update 2009 Appl Energy 2010;87(2):398-409. http://dx.doi.org/10.1016/i. apenergy.2009.08.014.

[6] Iglesias G, Sanchez M, Carballo R, Fernandez H. The TSE index: a new tool for selecting tidal stream sites in depth-limited regions. Renew Energy 2012;48:350-7. http://dx.doi.org/10.1016/i.renene.2012.05.012.

[7] Kadiri M, Ahmadian R, Bockelmann-Evans B, Rauen W, Falconer R. A review of the potential water quality impacts of tidal renewable energy systems. Renew
Sustain Energy Rev 2012;16(1):329-41. http://dx.doi.org/10.1016/i. rser.2011.07.160.

[8] Neill SP, Litt EJ, Couch SJ, Davies AG. The impact of tidal stream turbines on large-scale sediment dynamics. Renew Energy 2009;34(12):2803-12. http:/ dx.doi.org/10.1016/j.renene.2009.06.015.

[9] Sanchez M, Carballo R, Ramos V, Iglesias G. Tidal stream energy impact on the transient and residual flow in an estuary: a 3D analysis. Appl Energy 2014;116:167-77. http://dx.doi.org/10.1016/i.apenergy.2013.11.052.

[10] Zheng Jinhai, Dai Peng, Zhang Jisheng. Tidal stream energy in china. Proc Eng 2015;116:880-7. 8th International Conference on Asian and Pacific Coasts (APAC 2015). doi:http://dx.doi.org/10.1016/j.proeng.2015.08.377.

[11] Carballo R, Iglesias G, Castro A. Numerical model evaluation of tidal stream energy resources in the Ria de Muros (NW Spain). Renew Energy 2009;34 (6):1517-24. http://dx.doi.org/10.1016/j.renene.2008.10.028.

[12] Lewis $M$, Neill $S$, Robins $P$, Hashemi M. Resource assessment for future generations of tidal-stream energy arrays. Energy 2015;83:403-15. http://dx. doi.org/10.1016/j.energy.2015.02.038.

[13] Sanchez M, Carballo R, Ramos V, Iglesias G. Energy production from tidal currents in an estuary: a comparative study of floating and bottom-fixed turbines. Energy 2014;77:802-11. http://dx.doi.org/10.1016/j. energy.2014.09.053.

[14] Vazquez A, Iglesias G. A holistic method for selecting tidal stream energy hotspots under technical, economic and functional constraints. Energy Convers Manage 2016;117:420-30. http://dx.doi.org/10.1016/j. enconman.2016.03.012.

[15] IEC-TS 62600-201: Marine energy wave, tidal and other water current converters part 201: Tidal energy resource assessment and characterisation; 2014.

[16] Neill Simon P, Reza Hashemi M, Lewis Matt J. The role of tidal asymmetry in characterizing the tidal energy resource of Orkney. Renew Energy 2014;68:337-50. http://dx.doi.org/10.1016/j.renene.2014.01.052.

[17] Robins Peter E, Neill Simon P, Lewis Matt J, Ward Sophie L. Characterising the spatial and temporal variability of the tidal-stream energy resource over the northwest European shelf seas. Appl Energy 2015;147:510-22. http://dx.doi. org/10.1016/j.apenergy.2015.03.045.

[18] http://www.emec.org.uk/ [12 2004].

[19] Cornett A, Baker S, Toupin M, Piche S, Nistor I. Appraisal of IEC standards for wave and tidal energy resource assessment. In: International Conference on Ocean Energy (ICOE), November 4-6; 2014.

[20] Ramos V, Carballo R, Alvarez M, Sanchez M, Iglesias G. Assessment of the impacts of tidal stream energy through high-resolution numerical modeling. Energy 2013;61:541-54. http://dx.doi.org/10.1016/j.energy.2013.08.051.

[21] Hydraulics, Delft., Delft, the Netherlands. Delft3D-FLOW user manual; 2006.

[22] Ramos V, Carballo R, Sanchez M, Veigas M, Iglesias G. Tidal stream energy impacts on estuarine circulation. Energy Convers Manage 2014;80(0):137-49. http://dx.doi.org/10.1016/j.enconman.2014.01.027.

[23] Sanchez M, Carballo R, Ramos V, Iglesias G. Floating vs. bottom-fixed turbines for tidal stream energy: a comparative impact assessment. Energy 2014;72:691-701. http://dx.doi.org/10.1016/i.energy.2014.05.096.

[24] Baston S, Waldman S, Side J. Modelling energy extraction in tidal flows. MASTS Position Paper; 2015.

[25] Waldman S, Baston S, Nemalidinne R, Chatzirodou A, Venugopal V, Side J. Implementation of tidal turbines in MIKE 3 and Delft3D models of Pentland Firth \& Orkney Waters, in preparation.

[26] OceanFlowEnergy, http://www.oceanflowenergy.com/ [12 2010].

[27] Easton MC, Woolf DK, Bowyer PA. The dynamics of an energetic tidal channel, the pentland firth, scotland. Continental Shelf Res 2012;48:50-60. http://dx. doi.org/10.1016/i.csr.2012.08.009.

[28] Dushaw BD, Egbert GD, Worcester PF, Cornuelle BD, Howe BM, Metzger K. A topex/poseidon global tidal model (tpxo 7.2) and barotropic tidal currents determined from long-range acoustic transmissions. Prog Oceanogr 1997;40:337-67. http://dx.doi.org/10.1016/S0079-6611(98)00008-1. Tidal Science In Honour of David E. Cartwright.

[29] Cornett A, Toupin M, Nistor I. Appraisal of IEC technical specification for tidal energy resource assessment at minas passage, Bay of Fundy, Canada. In: Proceedings of the 11th European wave and tidal energy conference.

[30] Ramos V, Carballo R, Alvarez M, Sanchez M, Iglesias G. A port towards energy self-sufficiency using tidal stream power. Energy 2014;71:432-44. http://dx. doi.org/10.1016/j.energy.2014.04.098.

[31] Pawlowicz R, Beardsley B, Lentz S. Classical tidal harmonic analysis including error estimates in matlab using t_tide. Comput Geosci 2002;28(8):929-37. 